\title{
28 Research Square \\ Small Cell Carcinoma Esophagus: Experience of an Indian Tertiary Cancer Center
}

\section{Goutam Santosh Panda}

Tata Memorial Centre https://orcid.org/0000-0003-1393-8607

\section{Vanita Noronha}

Tata Memorial Centre

\section{Subhash Yadav}

Tata Memorial Centre

\section{Amit Joshi}

Tata Memorial Centre

\section{Vijay Patil}

Tata Memorial Centre

Nandini Menon

Tata Memorial Centre

Rajiv Kumar

Tata Memorial Centre

Amit Janu

Tata Memorial Centre

Abhishek Mahajan

Tata Memorial Centre

Nilendu Purandare

Tata Memorial Centre

Jai Prakash Agarwal

Tata Memorial Centre

George Karimundackal

Tata Memorial Centre

Kumar Prabhash ( $\sim$ kumarprabhashtmh@gmail.com )

Tata Memorial Centre

\section{Research Article}

Keywords: small cell carcinoma esophagus, systemic therapy, toxicity, outcome

Posted Date: July 28th, 2021 
DOI: https://doi.org/10.21203/rs.3.rs-621928/v2

License: (c) (1) This work is licensed under a Creative Commons Attribution 4.0 International License. Read Full License 


\section{Abstract}

Background: Small cell carcinoma of the esophagus (SCCE) is a rare and aggressive tumor with no established standard treatment.

Methods: This is a retrospective study of adult patients with histologically proven SCCE registered between February 2011 and March 2020 at Tata Memorial Hospital in Mumbai.

Results: There were 56 patients with 29(51.8\%) having limited-stage disease (LD) and 27(48.2\%) having extensive-stage disease (ED). The median age was 58(IQR 51-65) years, $57.1 \%$ were men, $40 \%$ were smokers. Amongst LD-SCCE patients, 23 underwent local therapy i.e. radiation $(19,65.5 \%)$, surgery (4, $13.8 \%)$ and 27 received chemotherapy in neoadjuvant $(23,79.3 \%)$, concurrent $(18,62.1 \%)$ and adjuvant $(4,13.8 \%)$ settings. Total 19 ED-SCCE patients (70.4\%) received chemotherapy. Prophylactic cranial irradiation (PCI) was delivered to $11(37.9 \%)$ and $7(25.9 \%)$ patients with LD-SCCE and ED-SCCE, respectively. Significant grade $\geq 3$ chemo-toxicities in patients with LD-SCCE and ED-SCCE included febrile neutropenia in $33.3 \%$ and $23.5 \%$, anemia in $9.5 \%$ and $17.6 \%$, and dyselectrolytemia in $14.3 \%$ and $11.8 \%$, respectively. The median overall survival (OS) in LD-SCCE and ED-SCCE were $22.9(95 \% \mathrm{Cl} 1.8$ 44.1) months and 11.8 ( $95 \% \mathrm{Cl} 7.3-16.4)$ months, respectively. Age <60years ( $p=0.004)$ and tumor epicenter in lower third esophagus $(p=0.002)$ were good prognostic factors for OS in LD-SCCE and EDSCCE patients respectively. The incidence of brain metastasis was low, both at presentation $(1 / 27,3.7 \%)$ and at relapse $(5 / 56,8.9 \%)$.

Conclusion: Although the median overall survival of LD-SCCE is better than ED-SCCE, it is still under 2 years. Brain metastases are uncommon and $\mathrm{PCl}$ can be avoided with close clinico-radiological follow up.

\section{Background}

Esophageal cancer is the sixth most common cancer with an incidence of 5.04\% in India as per WHO, GLOBOCAN 2018[1]. Squamous carcinoma and adenocarcinoma are the common histological types, while small cell carcinoma is rare, having an incidence of $0.1-2.4 \%$ of all esophageal cancers [2, 3]. SCCE is a highly aggressive malignancy, with approximately half of the patients presenting with metastatic disease[ $[3,4]$ and has a poor prognosis $[5,6]$.SCCE is thought to behave clinically similarly to small cell lung cancer (SCLC) and the management of SCCE is often extrapolated from small cell lung cancer. Chemotherapy, surgery and radiotherapy have been used with inconsistent outcomes. Randomized studies are not available owing to the rarity of this malignancy. Several retrospective studies have reported differences in survival depending on the treatment modality[3, 4].However data regarding toxicity is scarce .Hence, we retrospectively analysed the available clinical data of SCCE patients registered at our institute for treatment strategy, outcome, toxicity and reviewed the literature.gy.

\section{Methods}




\section{General study details}

This is a retrospective analysis of prospectively collected data of all adult patients (age $\geq 18$ years) with SCCE who registered at Tata Memorial Hospital in Mumbai, India, between February 2011 and March 2020. Patients with mixed tumors, i.e., SCCE with another histology like squamous carcinoma or adenocarcinoma, were also considered for this study. We excluded patients for whom no clinical details were available. Since the study was retrospective, ethics committee approval and informed consent were not required. No funding support was utilized. The study was conducted according to the ethical principles outlined in the Declaration of Helsinki and the Indian Council of Medical Research Good Clinical Practice Guidelines.

Our primary objective was to determine the overall survival (OS) of patients with SCCE. Our secondary objectives included determining the event-free survival (EFS), evaluating chemotherapy toxicity, and prognostic factors affecting survival.

\section{Study method:}

The patients included in the study were identified from the rare tumor database maintained in the Department of Medical Oncology and the records maintained in the Department of Pathology. We extracted the data for demographics, clinical and treatment-related details, chemotherapy-related toxicity, and survival data. SCCE was diagnosed using the histological criteria laid down by the World Health Organization (WHO) 2010 classification system[7], and the diagnosis was confirmed by synaptophysin and/or chromogranin A immunostaining.

Workup and management were decided in the multidisciplinary thoracic oncology disease management group tumor board. Tumors were staged as limited stage disease (LD) or extensive stage disease (ED) as per Veteran's Administration Lung Group (VALSG) staging system for SCLC[8]. The Union for International Cancer Control (UICC) 1987 standard was used to describe tumour location in the oesophagus. Also the eighth edition of the combined American Joint Committee on Cancer (AJCC)/UICC tumour, node, metastasis (TNM) staging system was used for esophageal cancer staging[9]. All preliminary evaluation details including the clinical history, physical examination, endoscopic upper gastrointestinal imaging findings, the epicenter of the tumor in the esophagus (cervical,upper-third, middle-third, lower-third, abdominal), and imaging results including computed tomography (CT), magnetic resonance imaging (MRI) brain and/or Fluorodeoxyglucose positron emission tomography and computed tomography (FDG PET-CT) findings, complete blood count (CBC), renal function tests (RFT), and liver function tests (LFT) were documented and entered into an excel sheet. The treatment strategies, use of prophylactic cranial irradiation (PCl), response to treatment as per Response Evaluation Criteria in Solid Tumors 1.1 (RECIST 1.1) and grade 3 or more toxic events as per Common Terminology Criteria for Adverse Events (CTCAE) v $4[10]$ were recorded.

\section{Statistical Analysis:}


Analysis was performed in the Statistical Package for the Social Sciences (IBM Corp. Released 2016. IBM SPSS Statistics for Windows, Version 24.0. Armonk, NY: IBM Corp.). Kaplan-Meier method was used for estimating survival and log-rank test was employed for comparison .Factors significant on univariate analysis were subsequently subjected to multivariate analysis using cox regression method.

EFS was calculated as the time from registration to the first event, where events included progression, recurrence, second malignancy or death. Censoring was done for patients who did not experience an event or were lost to follow up for $>6$ months by the end of the follow-up period. OS was calculated from date of registration until death from any cause or last documented follow-up with appropriate censoring. The data cut-off date was 10/12/2020.

\section{Results}

\section{Patients and tumor characteristics (Table 1)}


Table 1

Baseline characteristics

\begin{tabular}{|c|c|c|}
\hline Variable & $\begin{array}{l}\text { LD-SCCE, Number (\%), } \\
n=29\end{array}$ & $\begin{array}{l}\text { ED-SCCE, Number (\%), } \\
\mathrm{n}=\mathbf{2 7}\end{array}$ \\
\hline \multicolumn{3}{|l|}{ Patient characteristics } \\
\hline 1.Age(in years) & 58 & 57 \\
\hline Median & $50.5-66.5$ & $51-64$ \\
\hline \multicolumn{3}{|l|}{ Interquartile range(IQR) } \\
\hline 2.Sex & $18(62.1 \%)$ & $15(55.6 \%)$ \\
\hline Male & $11(37.9 \%)$ & $12(44.4 \%)$ \\
\hline \multicolumn{3}{|l|}{ Female } \\
\hline 3.Comorbidity & $14(48.3 \%)$ & $10(37.1 \%)$ \\
\hline Yes & $15(51.7 \%)$ & $17(62.9 \%)$ \\
\hline \multicolumn{3}{|l|}{ No } \\
\hline 4.ECOG PS & $28(96.5 \%)$ & $21(77.8 \%)$ \\
\hline $0-1$ & $1(3.5 \%)$ & $6(22.2 \%)$ \\
\hline \multicolumn{3}{|l|}{$\geq 2$} \\
\hline 5. Addiction* & $14(48.3 \%)$ & $11(40.7 \%)$ \\
\hline Tobacco chewer & $11(37.9 \%)$ & $12(44.4 \%)$ \\
\hline Smoker & $2(6.9 \%)$ & $5(18.5 \%)$ \\
\hline Alcohol & $4(13.8 \%)$ & $4(14.8 \%)$ \\
\hline \multicolumn{3}{|l|}{ None } \\
\hline \multicolumn{3}{|l|}{ Tumor characteristics } \\
\hline 6.Location & $4(13.8 \%)$ & $3(11.1 \%)$ \\
\hline Cervical + upper & $18(62.1 \%)$ & $13(48.1 \%)$ \\
\hline Middle & $7(24.1 \%)$ & $11(40.7 \%)$ \\
\hline \multicolumn{3}{|l|}{ Lower + GEJ } \\
\hline 7.Histology & $26(89.7 \%)$ & $25(92.6 \%)$ \\
\hline Pure small cell carcinoma & $3(10.3 \%)$ & $2(7.4 \%)$ \\
\hline Mixed histology & & \\
\hline
\end{tabular}




\begin{tabular}{|c|c|c|}
\hline Variable & $\begin{array}{l}\text { LD-SCCE, Number (\%), } \\
\mathrm{n}=29\end{array}$ & $\begin{array}{l}\text { ED-SCCE, Number (\%), } \\
n=27\end{array}$ \\
\hline 9. Median length in $\mathrm{cm}$ & 6.2 & 7.4 \\
\hline 10.Skip lesion & $1(3.4 \%)$ & $2(7.4 \%)$ \\
\hline Yes & $28(96.6 \%)$ & $25(92.6 \%)$ \\
\hline \multicolumn{3}{|l|}{ No } \\
\hline 11.Regional lymph node involvement & $26(89.7 \%)$ & $26(96.3 \%)$ \\
\hline Yes & $3(10.3 \%)$ & $1(3.7 \%)$ \\
\hline \multicolumn{3}{|l|}{ No } \\
\hline 12.Metastatic sites & NA & $17(62.9 \%)$ \\
\hline Liver & NA & $13(48.1 \%)$ \\
\hline Non-regional lymph node & NA & $7(25.9 \%)$ \\
\hline Lungs & NA & $6(22.2 \%)$ \\
\hline Bone & NA & $5(18.5 \%)$ \\
\hline Bone marrow & NA & $1(3.7 \%)$ \\
\hline \multicolumn{3}{|l|}{ Brain } \\
\hline 13.Number of metastatic sites & NA & $13(48.1 \%)$ \\
\hline 1 & NA & $7(25.9 \%)$ \\
\hline 2 & NA & $7(25.9 \%)$ \\
\hline \multicolumn{3}{|l|}{$\geq 3$} \\
\hline \multicolumn{3}{|l|}{ Laboratory parameters } \\
\hline \multicolumn{3}{|l|}{ Median (IQR) Median (IQR) } \\
\hline 14.Hemoglobin in $\mathrm{gm} / \mathrm{dl}$ & $12.3(11.3-14.3)$ & $12.6(11.6-14.1)$ \\
\hline 15.Albumin in gm/dl & $4.1(3.8-4.3)$ & $3.9(3.6-4.2)$ \\
\hline 16.Serum alkaline phosphatasein U/L & $98(81-113)$ & $112(87-148.5)$ \\
\hline 17.LDH in U/L & $170(152-196.5)$ & $328(203-689)$ \\
\hline
\end{tabular}

Abbreviations

LD-SCCE

Limited stage disease-small cell carcinoma esophagus 


\section{ED-SCCE}

Extensive stage disease-small cell carcinoma esophagus

ECOG PS

Eastern Co-operative Oncology Group performance status

GEJ

Gastro-esophageal junction

NA

Not applicable

$\mathrm{LDH}$

Lactate dehydrogenase

Of 8342 patients with esophageal malignancies, 59(0.7\%) had SCCE. No clinical details could be retrieved for 3 SCCE patients and they were therefore excluded. We included 56 patients in the study. Dysphagia (54 cases, 96.4\%) was the commonest presenting symptom with a median duration of 2 months before presentation. Two patients (3.6\%) had a family history of malignancy.

The tumors commonly arose in the middle and lower third of the esophagus. FDG PET-CT was done in $40(71.4 \%)$ patients, contrast-enhanced CT instead of PET-CT was done in $14(25 \%)$ as there was obvious metastasis in CT scan and 2 (3.6\%) patients defaulted before completion of staging work up .However, these 2 defaulters had CT thorax showing metastatic disease. Brain imaging at baseline was available as MRI brain in 14 (25\%) cases, FDG PET-CT in 30(53.6\%) cases, while in the remaining 12 patients (21.4\%) no cross-sectional brain imaging was available. Of the total of 56 patients analyzed, 29 (51.8\%) had LDSCCE, and 27 (48.2\%) had ED-SCCE.

\section{Pathology findings:}

The tumors showed uniform histology in all the cases, characterized by crushed hyperchromatic cells with scant to absent cytoplasm, prominent nuclear molding and absent to inconspicuous nucleoli. The immunohistochemistry panel utilized for diagnosis included synaptophysin, chromogranin and CD56. All patients had at least two of the above three positive to confirm the neuroendocrine nature of the tumor. The proliferation (Ki-67) index was high (> 70\%) in all these tumors (Supplementary Fig. 1).

\section{Treatment (Fig. 1)}

\section{LD-SCCE}

Of 29 patients, 28 (96.6\%) were considered for curative intent therapy while 1 patient (3.4\%) was declared best supportive care upfront because of poor Eastern Cooperative Oncology Group (ECOG) performance status (PS).Of 28 patients considered for tumor-directed therapy, local therapy was delivered in 23 (radiotherapy in 19, surgery in 4). The remaining 5 patients who were planned, but did not undergo any local therapy included 3 patients who defaulted post neoadjuvant chemotherapy (NACT) and 2 patients who died from chemotherapy-related toxicities on NACT. NACT and adjuvant chemotherapy were administered in $23(79.3 \%)$ and $4(13.8 \%)$ cases, respectively. Concurrent chemoradiation (CRT) was 
planned for all patients undergoing radiation as local therapy, except one patient, who was deemed unfit for chemotherapy. Eleven (37.9\%) patients received $\mathrm{PCl}$.

\section{ED-SCCE}

Although 24 of the 27 patients (88.9\%) with ED-SCCE were advised chemotherapy, 19 (70.4\%) received palliative chemotherapy and 7 (25.9\%) patients received $\mathrm{PCl}$.

\section{Chemotherapy:}

The once-in-3-weeks etoposide and platinum (cisplatin/carboplatin), EP doublet regimen was used in 44 of 46 patients (95.6\%) who received chemotherapy. Carboplatin was administered to $28(60.9 \%)$ [13 (28.3\%) with LD-SCCE and 15 (32.6\%) with ED-SCCE] of 46 patients receiving chemotherapy. The reasons

for using carboplatin instead of cisplatin included low glomerular filtration rate (GFR)[9 in LD-SCCE and 5 in ED-SCCE), advanced age and the clinician's judgment regarding chemotherapy tolerance[3 in LD-SCCE and 8 in ED-SCCE), comorbidity [1 in LD-SCCE and 2 in ED-SCCE). One patient received once-a-week paclitaxel and carboplatin as concurrent CRT and one received the same regimen in the palliative setting. The median number of EP cycles in patients with LD-SCCE and ED-SCCE were 4 and 6, respectively.

\section{Response Rate:}

Radiologic responses to treatment were available for 15 of $19(78.9 \%)$ patients with LD-SCCE undergoing non-surgical modality of therapy and 15 of $19(78.9 \%)$ patients with ED-SCCE who received chemotherapy. Responses in patients with LD-SCCE and ED-SCCE included complete response(CR) in $9(9 / 15,60 \%)$ and $2(2 / 15,13.3 \%)$, partial response in $5(5 / 15,33.3 \%)$ and $8(8 / 15,53.3 \%)$, stable disease $0(0 / 15)$ and $3(3 / 15,20 \%)$, and progressive disease in $1(1 / 15,6.67 \%)$ and $2(2 / 15,13.3 \%)$, respectively.

\section{Surgery:}

Five LD-SCCE patients were planned for surgery. Of these, four underwent esophagectomy with three-field lymph node dissection (cervical, mediastinal, and perigastric lymph nodes), while one patient defaulted post NACT. All 4 patients had RO resection and had received NACT with EP - 3cycles in two cases, 4 cycles in one case and 6 cycles in one case. Histopathology revealed scanty residual tumor in one case, one focus of in situ carcinoma in one case, while there was evidence of residual invasive carcinoma in the remaining two cases. None of these patients received adjuvant chemotherapy.

\section{Radiotherapy:}

The median dose of radiotherapy delivered as external beam radiotherapy (EBRT) in LD-SCCE was $63 \mathrm{~Gy} / 35 \#$ to loco-regional site. All received conventional fraction EBRT with 45Gy/25\# in one, $50.4 \mathrm{~Gy} / 28 \#$ in two, 55.8Gy/31\# in one, 59.4Gy/33\# in one, 60Gy/30\# in three and 63Gy/35\# in the remaining eleven patients. Two patients with ED-SCCE received palliative RT to the local site. The PCI dose regimens included $24.75 \mathrm{~Gy} / 11$ \# in six patients, $25 \mathrm{~Gy} / 10 \#$ and $24 \mathrm{~Gy} / 8 \#$ in two each with a median dose of $24.75 \mathrm{~Gy} / 11 \#$ in both LD and ED-SCCE. 


\section{Chemotherapy-related toxicities}

LD-SCCE: The toxicity data were available for 21 patients. Significant grade $\geq 3$ hematological toxicities were:febrile neutropenia (FN) in $7(7 / 21,33.3 \%)$, thrombocytopenia in $2(2 / 21,9.5 \%)$, and anemia in $2(2 / 21$, 9.5\%) while the non-hematological toxicities included-chemotherapy induced nausea and vomiting (CINV) and fatigue in 2 each (2/21,9.5\%), gastrointestinal (GI) toxicity in $4(4 / 21,19.0 \%)$, dyselectrolytemia in 3 $(3 / 21,14.3 \%)$, and hepatorenal syndrome in $1(1 / 21,4.8 \%)$. Four patients $(4 / 21,19 \%)$ required dose modification or omission during chemotherapy. Deaths attributable to chemotherapy occurred in 2 patients $(2 / 21,9.5 \%)$, one due to febrile neutropenia and another due to hepatorenal syndrome. Overall, 9 patients (42.9\%) experienced grade $\geq 3$ chemo-toxicity.

\section{ED-SCCE}

Toxicity data were available for 17 of 27 patients with ED-SCCE. Notable hematological grade $\geq 3$ toxicities were-FN in $4(4 / 17,23.5 \%)$, thrombocytopenia in $1(1 / 17,5.9 \%)$, and anemia in $3(3 / 17,17.6 \%)$, while the non-hematological toxicities included CINV in $1(1 / 17,5.9 \%)$,fatigue in $3(3 / 17,17.6 \%), G$ toxicity in $1(1 / 17,5.9 \%)$,dyselectrolytemia in $2(2 / 17,11.8 \%)$, and renal toxicity in $1(1 / 17,5.9 \%)$. Six $(6 / 17,35.3 \%)$ patients required dose modification or omission during chemotherapy. No patient with ED-SCCE died of chemotherapy toxicity. Overall, 10 patients (58.8\%) experienced grade $\geq 3$ chemotherapy related toxicity.

\section{Survival (Fig. 2)}

With a median follow up of 42.2(IQR, 20-61.5) months, the median EFS and OS for the entire cohort were $10.2(95 \% \mathrm{Cl} 7.5-12.9)$ months and $15.4(95 \% \mathrm{Cl} 12.7-18.2)$ months, respectively.

\section{LD-SCCE}

The median follow-up in surviving patients was 39.2(IQR 27.6-105.6) months.

A)EFS and patterns of failure: At the time of analysis, 22(75.9\%) patients experienced events for EFS (recurrence/progression/deaths:17/2/3).Of 19 recurrences/progressions, 2 had both locoregional and distant failures, and 17 had distant-only failures. Only 2 patients failed in the brain. The median EFS was $15.9(95 \% \mathrm{Cl}, 0-30.2)$ months. The estimated 3-year EFS was $30.5 \%$.

B)OS: There were 19 deaths, including the $2(2 / 29,6.9 \%)$ chemotherapy-toxic deaths and one $(1 / 29$, $3.5 \%)$ death due to sepsis post-surgery. The median OS was 22.9 ( $95 \% \mathrm{Cl} 1.8-44.1)$ months, and the 3year OS estimate was $41.7 \%$.

\section{ED-SCCE}

The median follow-up in surviving patients was 24.4(IQR 8.5-61.5) months. 
A) EFS and patterns of failure: At the time of analysis, 25 (92.6\%) patients had experienced events for EFS (recurrence:22; progression:2, death due to non-cancerous cause:1). The median EFS was 7.8 (95\% $\mathrm{Cl}, 6.6-9.0)$ months. The projected 3-year EFS was 3.9\%.

B) OS: The median OS was 11.8 (95\% Cl 7.3-16.4) months. The estimated OS at 3years was 3.9\%.

\section{Relapse in brain:}

Of all the patients with LD-SCCE, 18 (62.1\%) patients completed the planned therapy without disease progression and were advised PCl. However, some of these patients underwent PCl and some didn't. Similarly, PCI was considered for $10(37 \%)$ patients with ED-SCCE who did not have brain metastasis and attained CR or PR at the completion of the first line of chemotherapy. Of these 28 patients, 18 (18/28, 64.3\%) received PCI (LD-SCCE:11, ED-SCCE:7). A total of 5 patients relapsed in the brain(LD-SCCE:2, EDSCCE:3) (Supplementary Fig. 2)

\section{Prognostic factors (Table 2)}


Table 2

Significant factors of univariate and multivariate EFS and OS analysis

\begin{tabular}{|c|c|c|c|c|}
\hline & & $\begin{array}{l}\text { Whole cohort ( } \mathrm{n} \\
=56 \text { ) }\end{array}$ & $\begin{array}{l}\text { LD-SCCE }(n= \\
29)\end{array}$ & $\begin{array}{l}\text { ED-SCCE }(n= \\
\text { 27) }\end{array}$ \\
\hline & & {$[H R=, p=]$} & {$[H R, p=]$} & {$[H R, p=]$} \\
\hline \multicolumn{5}{|c|}{ EFS, univariate analysis } \\
\hline \multirow{2}{*}{$\begin{array}{l}\text { Age at diagnosis (in } \\
\text { years) }\end{array}$} & $\geq 60$ & - & & -- \\
\hline & $<60$ & -- & $\begin{array}{l}H R=0.2, p= \\
0.02\end{array}$ & - \\
\hline \multirow{2}{*}{$\begin{array}{l}\text { History of substance } \\
\text { abuse }\end{array}$} & Yes & & & - \\
\hline & No & $\begin{array}{l}\mathrm{HR}=0.3, \mathrm{p}= \\
0.004\end{array}$ & $\begin{array}{l}\mathrm{HR}=0.65, \mathrm{p}= \\
0.03\end{array}$ & -- \\
\hline \multirow[t]{2}{*}{ Gender } & Female & & - & -- \\
\hline & Male & $\begin{array}{l}\mathrm{HR}=0.5, \mathrm{p}= \\
0.006\end{array}$ & - & - \\
\hline \multirow[t]{2}{*}{ LDH } & Raised & & - & - \\
\hline & Not raised & $\begin{array}{l}\mathrm{HR}=0.3, \mathrm{p}= \\
0.004\end{array}$ & - & - \\
\hline \multirow[t]{2}{*}{ Intent of treatment } & Palliative & & - & - \\
\hline & Curative & $\begin{array}{l}\mathrm{HR}=0.3, \mathrm{p}< \\
0.001\end{array}$ & - & -- \\
\hline \multicolumn{5}{|c|}{ EFS, multivariate analysis } \\
\hline \multirow{2}{*}{$\begin{array}{l}\text { History of substance } \\
\text { abuse }\end{array}$} & Yes & & - & - \\
\hline & No & $\begin{array}{l}\mathrm{HR}=0.12, p= \\
0.001\end{array}$ & - & - \\
\hline \multicolumn{5}{|l|}{ OS, univariate analysis } \\
\hline \multirow{2}{*}{$\begin{array}{l}\text { Age at diagnosis (in } \\
\text { years) }\end{array}$} & $\geq 60$ & - & & \\
\hline & $<60$ & - & $\begin{array}{l}\mathrm{HR}=0.2, \mathrm{p}= \\
0.004\end{array}$ & - \\
\hline \multirow[t]{2}{*}{ ECOG PS } & $>1$ & & - & - \\
\hline & $0-1$ & $\begin{array}{l}\mathrm{HR}=0.44, p= \\
0.04\end{array}$ & - & - \\
\hline \multirow[t]{2}{*}{ Intent of treatment } & Palliative & & - & -- \\
\hline & Curative & $\mathrm{HR}=0.3, p=0.00$ & - & -- \\
\hline
\end{tabular}




\begin{tabular}{|c|c|c|c|c|}
\hline & & $\begin{array}{l}\text { Whole cohort (n } \\
=56 \text { ) }\end{array}$ & $\begin{array}{l}\text { LD-SCCE }(n= \\
29)\end{array}$ & $\begin{array}{l}\text { ED-SCCE( } \mathrm{n}= \\
\text { 27) }\end{array}$ \\
\hline \multirow[t]{2}{*}{ LDH } & Raised & & - & -- \\
\hline & Not raised & $\begin{array}{l}\mathrm{HR}=0.32, \mathrm{p}= \\
0.007\end{array}$ & - & - \\
\hline \multirow[t]{4}{*}{ Site of primary } & $\begin{array}{l}\text { Cervical, upper } \\
1 / 3 \text { rd }\end{array}$ & & - & \\
\hline & middle-third & & - & $\begin{array}{l}\text { worst } \\
\text { prognosis }\end{array}$ \\
\hline & $\begin{array}{l}\text { lower-third, } \\
\text { abdominal }\end{array}$ & & - & $\begin{array}{l}H R=0.3, p= \\
0.002\end{array}$ \\
\hline & & & & $\begin{array}{l}\text { (best } \\
\text { prognosis) }\end{array}$ \\
\hline \multicolumn{5}{|c|}{ OS, multivariate analysis } \\
\hline \multicolumn{5}{|c|}{ No significant prognostic factor } \\
\hline
\end{tabular}

Entire cohort: In univariate analysis, female sex, history of substance abuse, palliative intent treatment and raised LDH predicted for poorer EFS. History of substance abuse was the only independent prognostic factor for EFS while no factor independently prognosticated OS.

\section{Discussion}

In our SCCE cohort of 56 patients, the median OS was 22.9 (95\% Cl 1.8-44.1) months for LD-SCCE and 11.8 (95\% Cl 7.3-16.4) months for ED-SCCE. As per Ding et al. LD-SCCE patients, who underwent surgery and postoperative chemotherapy achieved a median OS of 26 months[11]. Moreover, the use of chemotherapy in combined modality treatment doubled the median OS from 11 months to 22 months $(H R=2.30, p=0.001)$. As per the published literature, the median OS of patients with LD-SCCE treated with a multimodality approach ranges from 14 months to as high as 39.7 months[6,11-13]. In our study, only one patient with LD-SCCE was offered single modality radical therapy (radiotherapy) as he was unfit for systemic therapy. Hence, we were unable to estimate the incremental benefit of systemic therapy in our patients with LD-SCCE. In a systematic analysis of 19 SCCE case series, the median OS in 88 patients with ED-SCCE was 9 months[14]. The OS of ED-SCCE was similar in other studies as well[5, 6, 14]. Thus, the outcomes of our patients with LD-SCCE and ED-SCCE were similar to those in the published literature.

In our study, approximately half the patients (30 of 66) had a history of either smoking or alcohol consumption. While there are no well-defined risk factors for SCCE, they appear to be similar to those for squamous cell esophageal cancer (history of alcohol consumption and smoking)[15]. Smoking has been identified as a significant risk factor in patients with SCLC, with a history of smoking being elicited in more than $90 \%$ of cases[16]. In our cohort of patients with SCCE, smoking appeared to be less important 
as an etiologic factor. As per the Global Adult Tobacco Survey, smoking is less common in India, with $19 \%$ of men and $2 \%$ of women being smokers[17].In our earlier studies, we had noted that $10-15 \%$ of our patients with SCLC and $55 \%$ of patients overall with lung cancer were non-smokers[18 HYPERLINK "https://paperpile.com/c/MEMnMb/nduFC+yxbrP+cpTQ5"- HYPERLINK "https://paperpile.com/c/MEMnMb/nduFC+yxbrP+cpTQ5"20].

The optimal loco-regional treatment for LD-SCCE is controversial. There are several reports and metaanalyses that recommend surgery as the local therapy of choice[2, 21, 22]. Regarding radiotherapy, several studies have reported that CRT can also achieve long-term survival in LD-SCCE patients[13, 23, 24]. A retrospective study that directly compared surgery and radiotherapy as local treatments found no difference in survival or loco-regional recurrence between patients treated with the two modalities[6].In our study, radiotherapy was the local treatment in a majority (65.5\%) of the LD-SCCE patients and surgery was the local treatment modality in only $4(13.8 \%)$ patients. Given the non-randomized nature and small sample size of this study, comparing the outcomes of patients treated with radiotherapy to surgery is inappropriate. However, the findings of our study indicate that CRT may be regarded as an alternative radical treatment strategy in LD-SCCE, with the benefit of preventing surgical complications and delaying the start of postoperative chemotherapy.

The most common chemotherapy-related toxicity was febrile neutropenia seen in $30 \%$ of patients in our study and the overall rate of grade $\geq 3$ toxicity was $50 \%$. In a study by Chen et al., the overall rate of grade 3-4 toxicities was $37.5 \%[13]$. There is a paucity of chemotherapy toxicity data as most studies are retrospective in nature and focused on outcomes rather than adverse events[12-14]. We observed that older age was associated with inferior OS in our LD-SCCE patients. Analysis of the SEER database had also revealed that older age was associated with a worse OS[3,25]. Other researchers have also made similar observations, albeit the association was not statistically significant $[13,26]$.Patients with a history of substance abuse had worse EFS in our cohort. However, a history of smoking had no impact on survival in other studies[13,27]. Amongst our patients with ED-SCCE, those with a primary in the lower third esophagus had better outcomes than others. An earlier study described origin in the middle third esophagus as a predictor for better OS in univariate analysis[27], while others did not find any significant correlation of primary tumor location and outcome[28,29]. Small sample sizes of the various studies and different tumor biology may be the reasons for the apparent differences in prognostic factors.

$\mathrm{PCl}$ is practiced in SCCE as an extrapolation of the data from SCLC, where the incidence of brain metastasis is as high as $50-80 \%$ at 2 years[30]. According to previous studies, the rate of brain metastasis in SCCE is 5-6\%, which is much lower than the rate in SCLC[23]. In our study, only 1 patient $(1 / 27,3.7 \%)$ with ED-SCCE had brain metastasis at presentation. We also observed the brain relapse rate was much lower than what has been historically reported in patients with SCLC. We observed the proportion of patients developing brain metastasis in both LD-SCCE and ED-SCCE were similar irrespective of $\mathrm{PCl}$. Hence, $\mathrm{PCl}$ may be cautiously avoided in patients with SCCE with close clinicoradiological follow up. This hypothesis is supported by other studies as well[5, 12]. 
The main limitations of our study are the small sample size, retrospective nature and single-institution study. Since none of our patients received immunotherapy, we are unable to determine the efficacy of immune checkpoint inhibitors in SCCE. Some of the records, such as those relating to past history, environmental exposures and quality of life, were limited. The availability of detailed systemic therapy toxicity data in the majority of patients is the strength of our study. The rarity of this malignancy makes the conduct of a randomized trial difficult. In such cases, retrospective studies and clinicians' experiences become important means to guide management.

\section{Conclusion}

Although the survival of LD-SCCE is better than ED-SCCE, it is still under 2 years with ample room for improvement .Brain metastasis is not common and $\mathrm{PCl}$ can be avoided in patients who are reliable for close clinico-radiological follow up. National and international collaboration is needed to conduct prospective studies to bridge the gap in the knowledge of treatment and prognostic factors in this rare tumor.

\section{Declarations}

Funding: No research support was received for this study

Conflicts of interest/Competing interests: The authors declare that they have no known competing financial interests or personal relationships that could have appeared to influence the work reported in this paper.

Availability of data and material: The data that support the findings of this study are available on request from the corresponding author. The data are not publicly available due to privacy or ethical restrictions.

Ethics Committee approval: Not required. The study was conducted according to the ethical principles outlined in the Declaration of Helsinki and the Indian Council of Medical Research Good Clinical Practice Guidelines.

Informed Consent: Not required

\section{Authors' contributions}

Study concepts: Dr. Vanita Noronha, Dr Kumar Prabhash, Dr Subhash Yadav ,Dr Rajiv Kumar, Dr Amit Joshi, Dr Goutam Panda

Study design: Dr Goutam Santosh Panda ,Dr. Vanita Noronha, Dr Kumar Prabhash.

Data acquisition: Dr Goutam Santosh Panda ,Dr. Vanita Noronha, Dr Subhash Yadav, Dr Rajiv Kumar, Dr Amit Joshi, Dr Kumar Prabhash 
Quality control of data and algorithms: Dr. Vanita Noronha, Dr Goutam Santosh Panda

Data analysis and interpretation: Dr. Vanita Noronha, Dr Goutam Santosh Panda, Dr Kumar Prabhash , Dr Jai Prakash Agarwal, Dr. George Karimundackal ,Dr Amit Joshi, Dr Vijay Patil , Dr Nandini Menon, Dr Amit Janu, Dr Nilendu Purandare, Dr Abhishek Mahajan

Statistical analysis: Dr Goutam Santosh Panda, Dr Vanita Noronha, Dr Kumar Prabhash, Dr Vijay Patil. Manuscript preparation: Dr Goutam Santosh Panda, Dr Vanita Noronha, Dr Subhash Yadav, Dr Kumar Prabhash, Dr Jai Prakash Agarwal, Dr. George Karimundackal ,Dr Amit Joshi, Dr Vijay Patil , Dr Nandini Menon, Dr Amit Janu, Dr Nilendu Purandare, Dr Abhishek Mahajan , Dr Rajiv Kumar.

Manuscript editing: Dr Goutam Santosh Panda, Dr Vanita Noronha, Dr Kumar Prabhash , Dr Amit Joshi, Dr Vijay Patil , Dr Nandini Menon ,Dr Subhash Yadav , Dr Rajiv Kumar, Dr Jai Prakash Agarwal,Dr. George Karimundackal,

\section{References}

1. Bray F, Ferlay J, Soerjomataram I, Siegel RL, Torre LA, Jemal A. Global cancer statistics 2018 : GLOBOCAN estimates of incidence and mortality worldwide for 36 cancers in 185 countries. CA Cancer J Clin. 2018;68:394-424. doi:10.3322/caac.21492.

2. Brenner B, Tang LH, Klimstra DS, Kelsen DP. Small-cell carcinomas of the gastrointestinal tract: a review. J Clin Oncol. 2004;22:2730-9. doi:10.1200/JC0.2004.09.075.

3. Kukar M, Groman A, Malhotra U, et al. Small cell carcinoma of the esophagus: a SEER database analysis. Ann Surg Oncol. 2013;20:4239-44. doi:10.1245/s10434-013-3167-3.

4. Wong AT, Shao M, Rineer J, Osborn V, Schwartz D, Schreiber D. Treatment and survival outcomes of small cell carcinoma of the esophagus: an analysis of the National Cancer Data Base. Dis Esophagus. 2017;30:1-5. doi:10.1111/dote.12487.

5. Zhu Y, Qiu B, Liu H, et al. Primary small cell carcinoma of the esophagus: review of 64 cases from a single institution. Dis Esophagus. 2014;27:152-8. doi:10.1111/dote.12069.

6. Lv J, Liang J, Wang J, et al. Primary small cell carcinoma of the esophagus. J Thorac Oncol. 2008;3:1460-5. doi:10.1097/JT0.0b013e31818e1247.

7. World Health Organization. WHO Classification of Tumours of the Digestive System. International Agency for Research on Cancer; 2010. Available: https://play.google.com/store/books/details? id=yo1TZp23Y8oC.

8. Sasajima K, Watanabe M, Ando T, et al. Serum neuron-specific enolase as a marker of small-cell carcinoma of the esophagus. J Clin Gastroenterol. 1990;12:384-8. doi:10.1097/00004836$199008000-00005$.

9. Rice TW, Patil DT, Blackstone EH. 8th edition AJCC/UICC staging of cancers of the esophagus and esophagogastric junction: application to clinical practice. Ann Cardiothorac Surg. 2017;6:119-30. doi:10.21037/acs.2017.03.14. 
10. 4. V. Common Terminology Criteria for Adverse Events (CTCAE). Available: https://www.eortc.be/services/doc/ctc/CTCAE_4.03_2010-06-14_QuickReference_5x7.pdf.

11. Ding J, Ji J, Zhu W, et al. A retrospective study of different treatments of limited-stage small-cell esophageal carcinoma and associated prognostic factor analysis. Dis Esophagus. 2013;26:696702. doi:10.1111/dote. 12017.

12. Jeene PM, Geijsen ED, Muijs CT, et al. Small Cell Carcinoma of the Esophagus: A Nationwide Analysis of Treatment and Outcome at Patient Level in Locoregional Disease. Am J Clin Oncol. 2019;42:534-8. doi:10.1097/COC.0000000000000546.

13. Chen $B$, Yang $H, M a ~ H$, et al. Radiotherapy for small cell carcinoma of the esophagus: outcomes and prognostic factors from a retrospective study. Radiat Oncol. 2019;14:210. doi:10.1186/s13014-0191415-9.

14. Gao R, Zhang Y, Wen XP, Fu J, Zhang GJ. Chemotherapy with cisplatin or carboplatin in combination with etoposide for small-cell esophageal cancer: a systemic analysis of case series. Dis Esophagus. 2014;27:764-9. doi:10.1111/dote.12149.

15. Hosokawa A, Shimada Y, Matsumura Y, et al. Small cell carcinoma of the esophagus. Analysis of 14 cases and literature review. Hepatogastroenterology. 2005;52: 1738-1741. Available: https://www.ncbi.nlm.nih.gov/pubmed/16334769.

16. Chen J, Qi Y, Wampfler JA, et al. Effect of cigarette smoking on quality of life in small cell lung cancer patients. Eur J Cancer. 2012;48:1593-601. doi:10.1016/j.ejca.2011.12.002.

17. Objectives G, Highlights G 2. GATS 2 global adult tobacco survey. [cited 19 Mar 2021]. Available: https://www.who.int/tobacco/surveillance/survey/gats/GATS_India_2016-17_FactSheet.pdf? ua=1\#:\%06:text=19.0\%25\%20of\%20men\%2C\%202.0\%25,and\%2For\%20smokeless\%20tobacco.

18. Noronha V, Ravind R, Patil VM, et al. The role of chemotherapy in patients with small cell lung cancer and poor performance status. Acta Oncol. 2020;59:1520-7. doi:10.1080/0284186X.2020.1819562.

19. Noronha V, Chougule A, Joshi A, Kumar R, Patil VM, Prabhash K. Epidermal Growth Factor Receptor Mutation in Small Cell Lung Cancer Patients in an Indian Tertiary Care Oncology Hospital: Incidence and Clinical Outcome. Clin Oncol. 2016;28:342-3. doi:10.1016/j.clon.2015.11.013.

20. Noronha V, Dikshit R, Raut N, et al. Epidemiology of lung cancer in India: focus on the differences between non-smokers and smokers: a single-centre experience. Indian J Cancer. 2012;49:74-81. doi:10.4103/0019-509X.98925.

21. Brock MV, Hooker CM, Syphard JE, et al. Surgical resection of limited disease small cell lung cancer in the new era of platinum chemotherapy: Its time has come. J Thorac Cardiovasc Surg. 2005;129:64-72. doi:10.1016/j.jtcvs.2004.08.022.

22. Tanaka T, Matono S, Nagano T, et al. Surgical management for small cell carcinoma of the esophagus. Dis Esophagus. 2010;23:502-5. doi:10.1111/j.1442-2050.2009.01045.x.

23. Ku GY, Minsky BD, Rusch VW, Bains M, Kelsen DP, Ilson DH. Small-cell carcinoma of the esophagus and gastroesophageal junction: review of the Memorial Sloan-Kettering experience. Ann Oncol. 2008;19:533-7. doi:10.1093/annonc/mdm476. 
24. Hudson E, Powell J, Mukherjee S, et al. Small cell oesophageal carcinoma: an institutional experience and review of the literature. Br J Cancer. 2007;96:708-11. doi:10.1038/sj.bjc.6603611.

25. Li T, Chen S, Zhang Z, et al. Chemotherapy Plus Radiotherapy Versus Radiotherapy in Patients With Small Cell Carcinoma of the Esophagus: A SEER Database Analysis. Cancer Control. 2021;28:1073274821989321. doi:10.1177/1073274821989321.

26. Hou X, Wei J-C, Wu J-X, et al. Multidisciplinary modalities achieve encouraging long-term survival in resectable limited-disease esophageal small cell carcinoma. PLoS One. 2013;8:e69259. doi:10.1371/journal.pone.0069259.

27. Xu L, Li Y, Liu X, et al. Treatment Strategies and Prognostic Factors of Limited-Stage Primary Small Cell Carcinoma of the Esophagus. J Thorac Oncol. 2017;12:1834-44. doi:10.1016/j.jtho.2017.09.1966.

28. Li J, Ma J, Wang H, Niu J, Zhou L. Population-based analysis of small cell carcinoma of the esophagus using the SEER database. J Thorac Dis. 2020;12:3529-38. doi:10.21037/jtd-20-1428.

29. Hosseini S, Salek R, Nasrolahi H, Mohammadianpanah M, Judi M. Small Cell Carcinoma of the Esophagus: Clinicopathological Features and Outcome of 22 Cases. Iran Red Crescent Med J. 2015;17:e20353. doi:10.5812/ircmj.20353.

30. Aupérin A, Arriagada R, Pignon JP, et al. Prophylactic cranial irradiation for patients with small-cell lung cancer in complete remission. Prophylactic Cranial Irradiation Overview Collaborative Group. N Engl J Med. 1999;341:476-84. doi:10.1056/NEJM199908123410703.

\section{Figures}




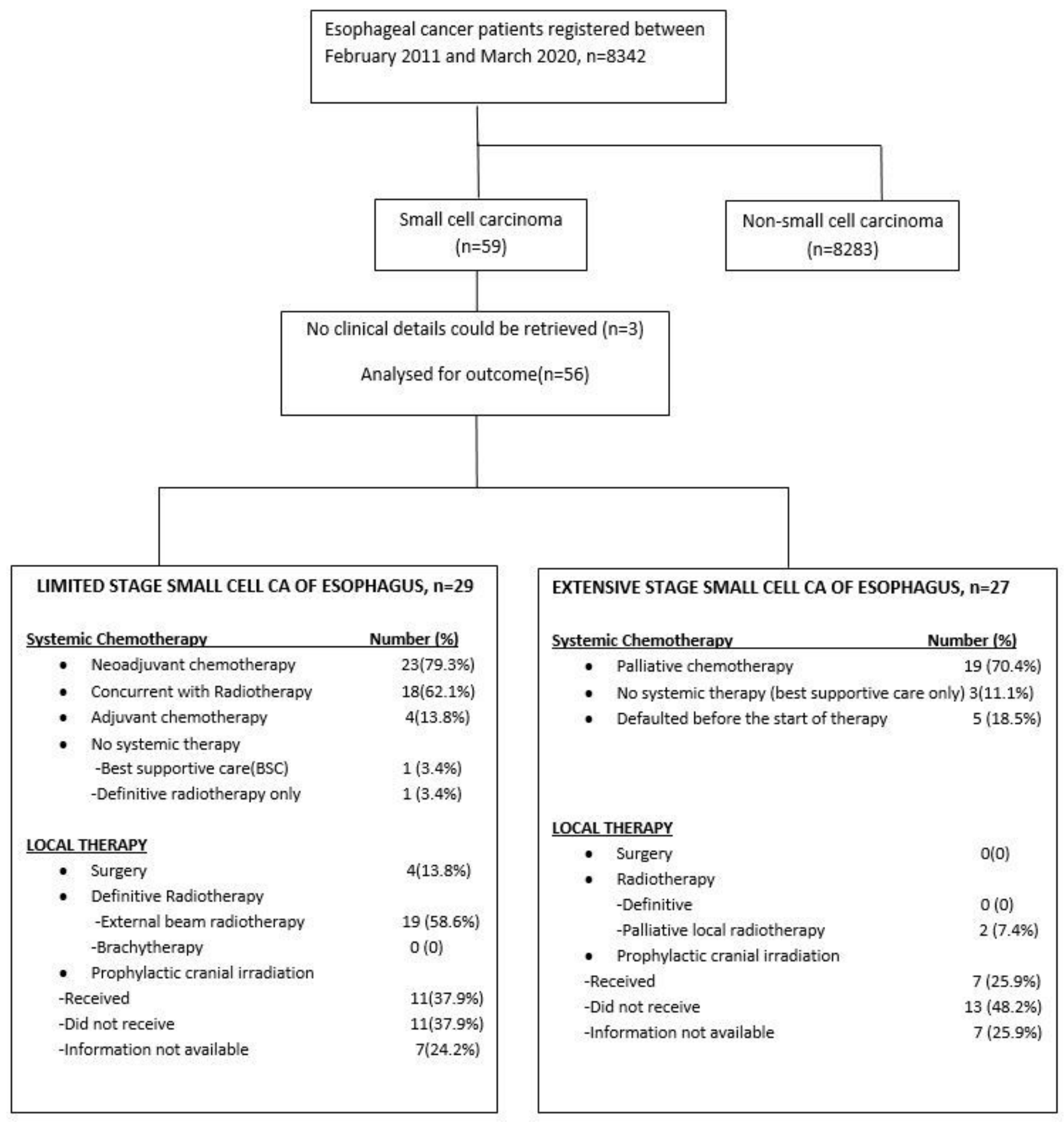

\section{Figure 1}

Treatment details of small cell carcinoma esophagus 

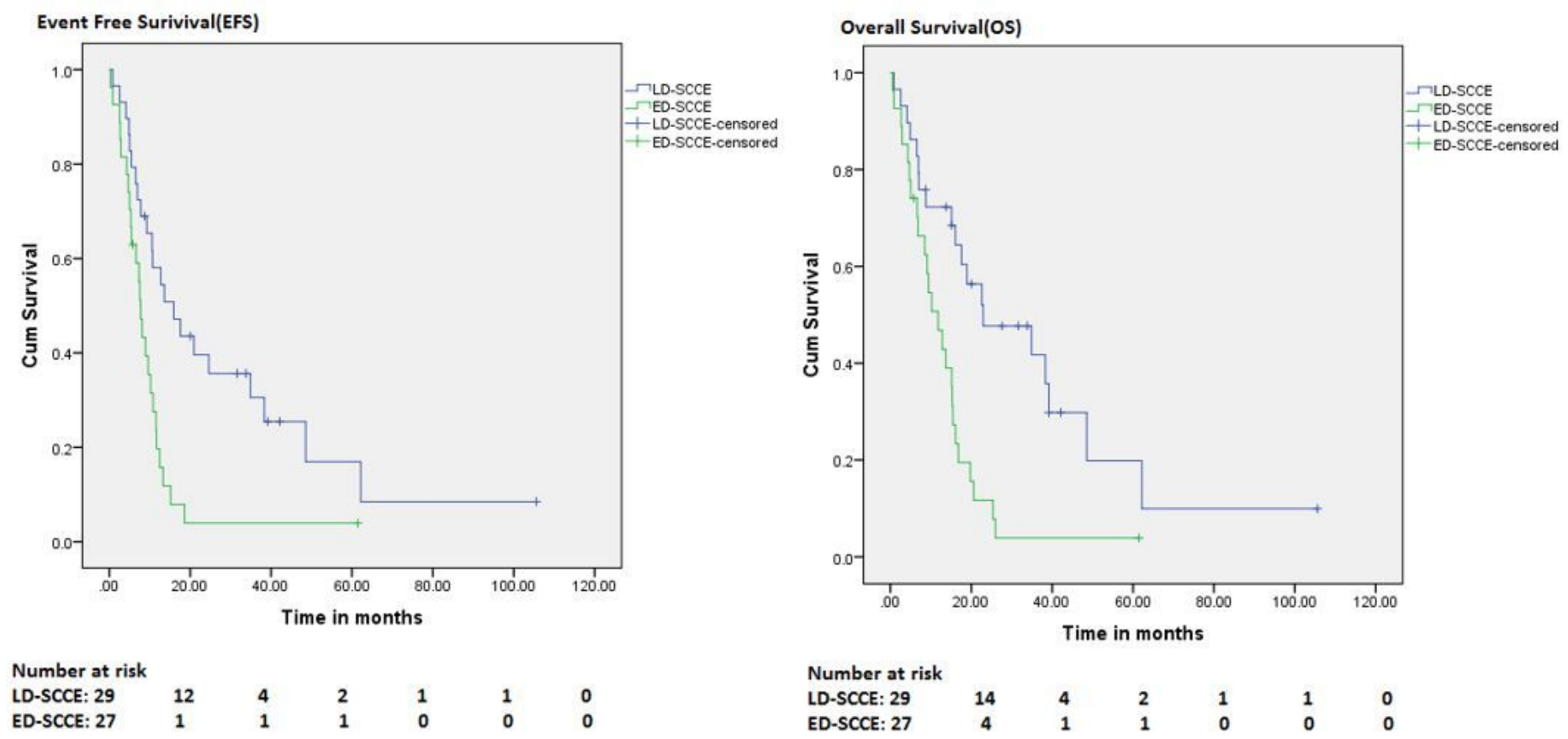

(Figure 3A)

(Figure 3B)

\section{Figure 2}

Event free survival (EFS)-Figure 3A and Overall survival (OS)-Figure 3B of limited stage disease small cell carcinoma esophagus (LD-SCCE) and extensive stage disease small cell carcinoma esophagus (EDSCCE)

\section{Supplementary Files}

This is a list of supplementary files associated with this preprint. Click to download.

- SuppFigure1.docx

- SuppFigure2.docx 